\title{
Estimating of the size of subsides for the use of hydrogen energy technologies for potential consumers
}

\author{
A.S. Grachev ${ }^{1, *}$ \\ ${ }^{1}$ Melentiev Energy Systems Institute Siberian Branch of the Russian Academy of Sciences Irkutsk, Russian Federation
}

\begin{abstract}
This article discusses the prospects for the use of hydrogen technologies in conjunction with renewable energy sources. A sim plified model of the power system of an isolated consumer using hydrogen technologies has been compiled. An experimental calculation of the electrical part of the system has been carried out. Based on the results obtained, conclusions are drawn about the further improvement of this model.
\end{abstract}

\section{Introduction}

Hydrogen energy is a promising area for development. Hydrogen is used in it for storage, transportation, generation and consumption of energy. The main advantages of using hydrogen are that it has a high calorific value, can be used as a long-term energy storage device, and does not emit $\mathrm{CO} 2$ or other toxic gases when burned. The use of internal combustion engines running on hydrogen in transport can be more profitable than the use of classic engines and electric motors [1-3].

Russia has great potential for production hydrogen and the development of hydrogen technologies in general. It is due to both the already commissioned RES capacities and the planned ones. As well as the presence of nuclear power that can be used to produce hydrogen. Russia has a well-developed gas infrastructure, which, after certain upgrades, will make it possible to supply hydrogen through the existing gas pipelines. In Russia, there are developments in terms of industrial production and use of hydrogen; it is enough to cite the defense and space industries as an example.

The main energy base for the production of hydrogen should be renewable energy sources, because green hydrogen will account for the main demand of consumer countries. The development of hydrogen energy will spur the improvement of renewable energy technologies and the development of the scale of their production, which gives reason to believe that Russia in the future may become an exporter of renewable energy equipment and hydrogen energy to interested states. All of the above factors allow us to conclude that in Russia, hydrogen technologies should be developed in conjunction with power plants based on renewable energy sources [4-6].

Pilot projects of energy supply to consumers using hydrogen technologies can be implemented in isolated power systems. At the initial stage, such projects cannot compete with classical projects, and will not pay off, the levelised cost of energy LCOE (1.1) will be too high for the consumer.
In order for the projects of hydrogen energy systems to pay off, subsidies from the state are needed. In this case, consumers will receive the same amount of energy services as in the case of the classical layout of isolated power systems.

$$
L C O E=\frac{\frac{\sum_{t=1}^{T}(K+M)}{(1+r)^{t-1}}}{\frac{\sum_{t=1}^{T} E}{(1+r)^{t-1}}},
$$

where $K$ - capital investments for year $t, M$ - fixed and variable costs for year $t, E$ - electricity production for year $t, r$-discount rate, $T$ - life cycle of the system.

\section{Model of the power system of an isolated consumer}

The approximate composition of the power system model for an isolated consumer using hydrogen technologies is shown in Fig. 1. The red frame, under the number 1, marks the classic system with a diesel generator (DG), renewable energy, battery and consumer. The blue frame, under the number 2, marks the system using hydrogen technologies. Generation sources in the system are diesel generators and renewable energy sources. Hydrogen acts as a storage device for energy and fuel for transport. We generate heat energy for consumers using an electric boiler, as well as take heat from a fuel cell (FC) and from a diesel generator. Removal of energy from the FC and diesel generator and then to the consumer.

Consider the electrical part of the model in Fig. 1, it is shown in Fig. 2. The model simulates the annual cycle of the power system operation, it includes 8760 intervals of 1 hour duration. This model has three states, which will be discussed below.

The model consists of generation (WPP), DG, storage batteries and hydrogen as a storage device. The

* Corresponding author: a.grachev@ @isem.irk.ru 
efficiency of the battery charge - discharge cycle is taken $\eta_{A B}=90 \%$, the efficiency of the cycle is the conversion of energy into hydrogen $(80 \%)$ and hydrogen into electricity (50\%), the final efficiency $\eta_{H_{2}}=40 \%$.

Excess energy is stored in $\mathrm{AB}$ and hydrogen in a ratio of $50 \%$ to $50 \%$, respectively. Taking into account the efficiency of storage devices, it is important to note that the stored energy in $\mathrm{AB}$ and in hydrogen has a ratio of $69.23 \%$ to $30.77 \%$, respectively. The amount of stored energy in the storage $W_{\sum_{H_{2}}}$ and $W_{\sum A B}$ devices is limited in the model by the parameter maximal storage capacity (2.1):

$$
\begin{gathered}
W_{\sum_{\text {STORMAX }}}= \\
=W_{\sum_{H_{2} M A X}}+W_{\sum A B M A X}, M W \cdot h
\end{gathered}
$$

In a situation when the energy reserves in the storage devices run out, and the deficit in the network remains,

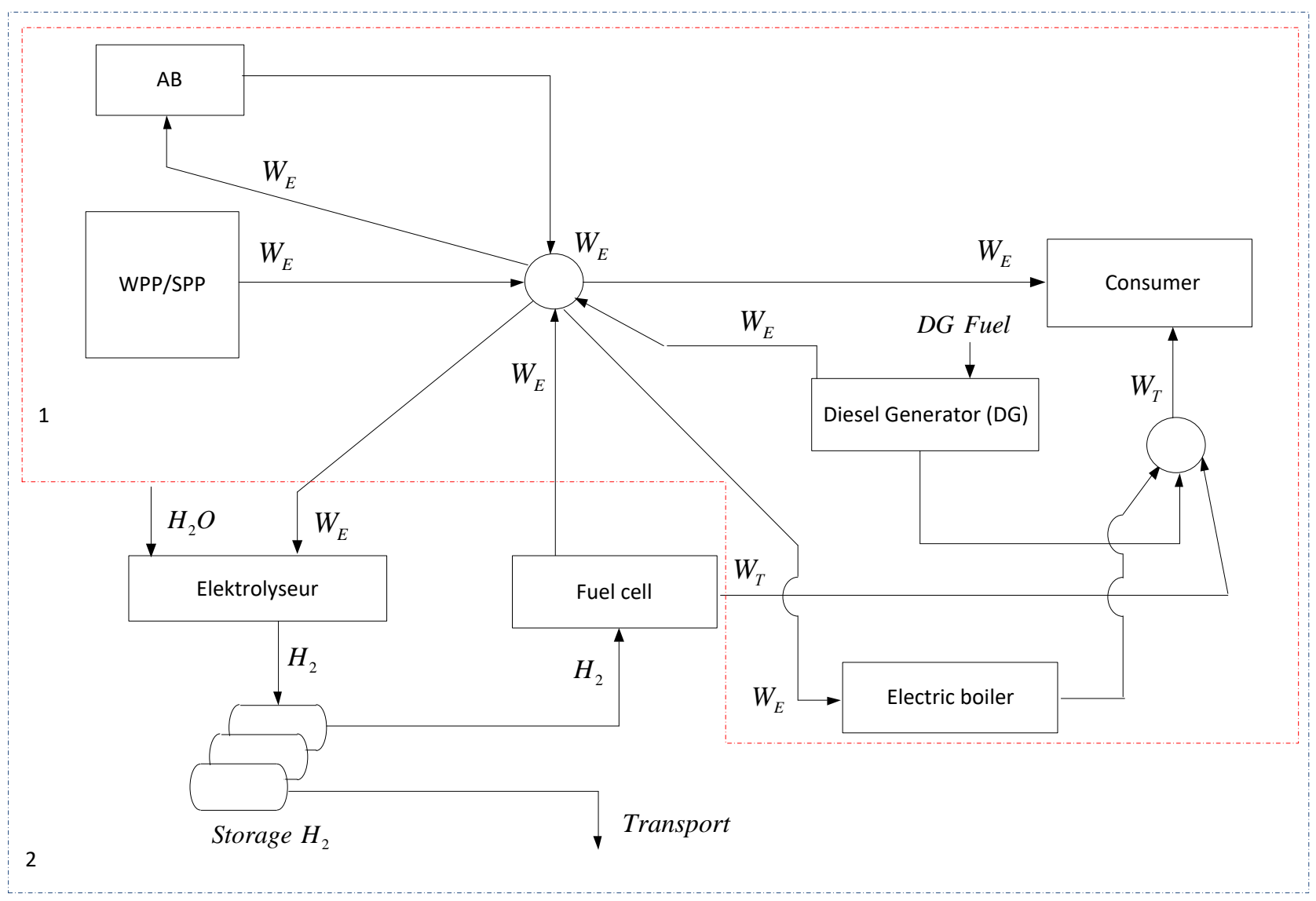

Fig. 1. Model of the power system of an isolated consumer: 1 - without the use of hydrogen technologies; 2 - using hydrogen technologies

the DG is connected to the network and begins to compensate for the deficit. The mathematical description of all possible states of a model of an isolated system using hydrogen technologies is given in the formulas below (2.2-2.14).

The first State of the model is shown in Fig. 2:

$$
\begin{gathered}
\text { If } P_{i G}>P_{i C} \text {, then } \\
P_{i \sum D G}=0 ; \\
P_{i \sum \text { Cons. Green. } H 2}=0 ; \\
P_{i \sum \text { Cons. } A B}=0 ; \\
W_{i \sum \text { Cons. }}=W_{i-1 \sum \text { Cons. }}+W_{i \sum A B} \\
+W_{i \sum H_{2}}=W_{i-1 \sum \text { Cons. }}+
\end{gathered}
$$

$$
\begin{gathered}
\frac{\left(P_{i G}-P_{i C}\right) \cdot N \cdot \eta_{A B}}{2}+ \\
+\frac{\left(P_{i G}-P_{i C}\right) \cdot N \cdot \eta_{H_{2}}}{2} ; \\
\text { If } W_{i \sum \text { Cons. }} \geq W_{i \sum \text { Cons.MAX }} \text {, then } \\
W_{i \sum \text { Cons. }}=W_{i \sum \text { Cons.MAX }},
\end{gathered}
$$

where $P_{i \sum D G}-$ total production of diesel generators for the $i$ interval; $P_{i \sum \text { Cons. Green.H2 }}$ - total consumption of green hydrogen for $i$ interval; $P_{i \sum \text { Cons. } A B}-$ total energy consumption from the $\mathrm{AB}$ for the $\mathrm{i}$ interval; $W_{i \sum \text { Cons. }}$ total energy in storage devices for i interval; $N$ - time interval equal to 1 hour. 


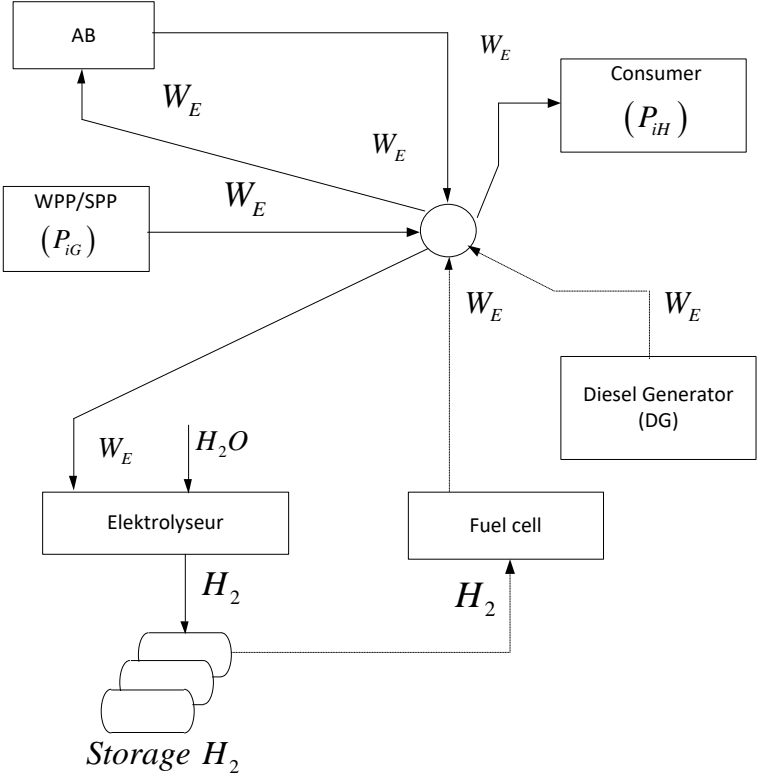

Fig. 2. The first state of the electrical model of the power system of an isolated consumer

The second state of the model is shown in Fig. 3:

$$
\begin{gathered}
\text { If } P_{i G}<P_{i C}, \text { and } \\
W_{i \sum \text { Cons. }}-P_{i C} \cdot N>0 \text {, then } \\
P_{i \sum D G}=0 \\
P_{i \sum \text { Cons. Green. } 2 .}= \\
=0,3077 \cdot\left(P_{i H}-P_{i G}\right) \\
P_{i \sum \text { Cons. } A B}= \\
=0,6923 \cdot\left(P_{i C}-P_{i G}\right) \\
=W_{i-1 \sum \text { Cons. }}- \\
W_{i \sum \text { Cons. }} \\
-W_{i \sum \text { Cons. } A B}-W_{i \sum \text { Cons. Green. } H 2} \cdot
\end{gathered}
$$

The third state of the model is shown in Fig. 4:

$$
\begin{gathered}
\text { Если } P_{i G}<P_{i C}, \text { и } \\
W_{i \sum \text { Cons. }}-P_{i C} \cdot N<0 \text {, то } \\
P_{i \sum D G}=P_{i C}- \\
P_{i \sum \text { Cons. Green.H } 2}-P_{i \sum \text { Cons. AB }} ; \\
P_{i \sum \text { Cons. Green. } \mathrm{H} 2}= \\
=0,3077 \cdot \frac{W_{i-1} \sum_{\text {Cons. }}}{N} ; \\
P_{i \sum \text { Cons. AB }}= \\
=0,6923 \cdot \frac{W_{i-1 \sum \text { Cons. }}}{N} ; \\
W_{i \sum \text { Cons. }}=0 .
\end{gathered}
$$

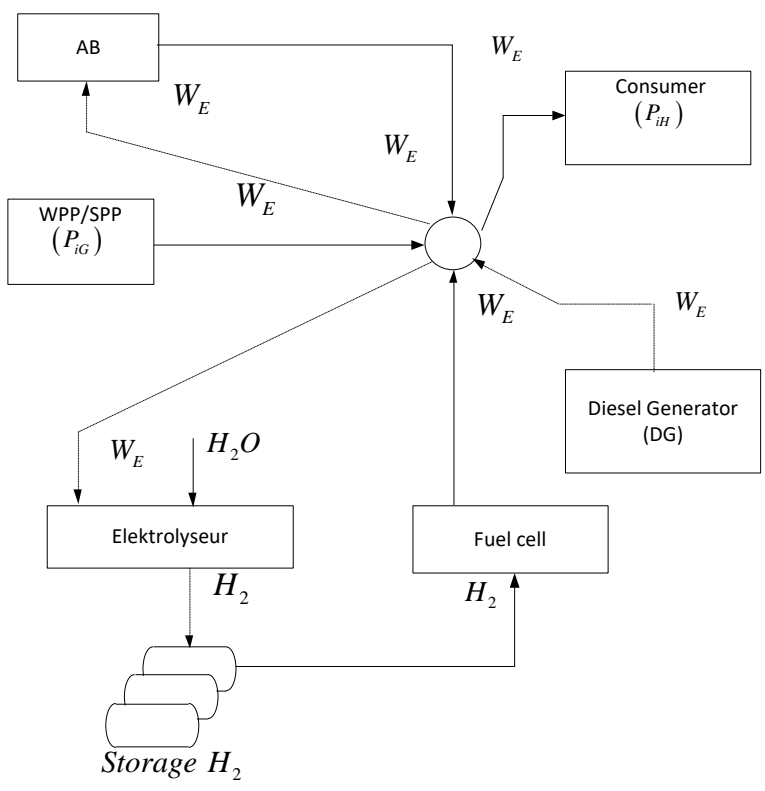

Fig. 3. The second state of the electrical model of the power system of an isolated consumer

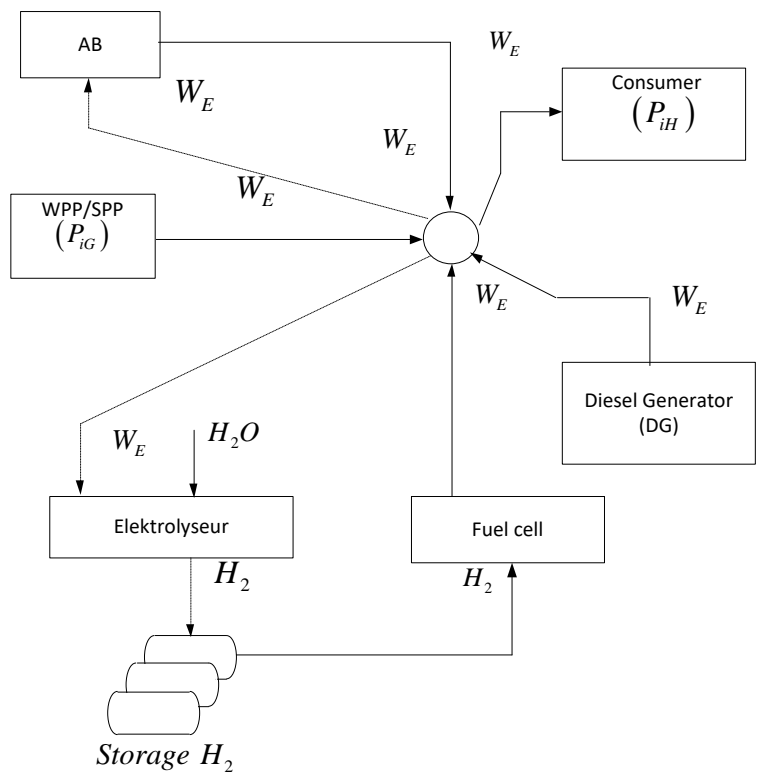

Fig. 4. The third state of the electrical model of the power system of an isolated consumer

We simulate the wind speed in the area of the wind farm for 8760 hours using a random number generator.

$$
\begin{gathered}
P_{\text {Wind turbine }}(t)=A \cdot V^{3} \cdot \eta_{\text {Wind turbine }} \cdot 0,5[\mathrm{~W}] ; \\
A=\pi \cdot r^{2}\left[\mathcal{M}^{2}\right],
\end{gathered}
$$

where $r$ - wind wheel radius, $V$ - wind speed, $\eta_{\text {Wind turbine }}$ - efficiency of a wind power plant (take 0,42)

We can see load schedules for each month on table 1 and fig. 5. Set the limit for storage capacity to 100 $\mathrm{MW} \cdot \mathrm{H}$ 
Table 1. Consumer electrical load graphs by month

\begin{tabular}{|c|c|c|c|c|c|c|c|c|c|c|c|c|}
\hline $\begin{array}{c}\text { Month } \\
\text { Hour }\end{array}$ & Jan. & Feb. & Mar. & Apr. & May & Jun. & Jul. & Aug. & Sep. & Oct. & Nov. & Dec. \\
\hline 1 & 8 & 8,5 & 8 & 8 & 6 & 3 & 3 & 5 & 6 & 6 & 7 & 8 \\
\hline 2 & 7 & 7,5 & 7 & 7 & 5 & 2 & 2 & 4 & 5 & 5 & 6 & 7 \\
\hline 3 & 7,5 & 8 & 7,5 & 7,5 & 5,5 & 2,5 & 2,5 & 4,5 & 5,5 & 5,5 & 6,5 & 7,5 \\
\hline 4 & 7,5 & 8 & 7,5 & 7,5 & 5,5 & 2,5 & 2,5 & 4,5 & 5,5 & 5,5 & 6,5 & 7,5 \\
\hline 5 & 8 & 8,5 & 8 & 8 & 6 & 3 & 3 & 5 & 6 & 6 & 7 & 8 \\
\hline 6 & 8 & 8,5 & 8 & 8 & 6 & 3 & 3 & 5 & 6 & 6 & 7 & 8 \\
\hline 7 & 10 & 10,5 & 10 & 10 & 8 & 5 & 5 & 7 & 8 & 8 & 9 & 10 \\
\hline 8 & 10 & 10,5 & 10 & 10 & 8 & 5 & 5 & 7 & 8 & 8 & 9 & 10 \\
\hline 9 & 12,5 & 13 & 12,5 & 12,5 & 10,5 & 7,5 & 7,5 & 9,5 & 10,5 & 10,5 & 11,5 & 12,5 \\
\hline 10 & 12,5 & 13 & 12,5 & 12,5 & 10,5 & 7,5 & 7,5 & 9,5 & 10,5 & 10,5 & 11,5 & 12,5 \\
\hline 11 & 14 & 14,5 & 14 & 14 & 12 & 9 & 9 & 11 & 12 & 12 & 13 & 14 \\
\hline 12 & 14 & 14,5 & 14 & 14 & 12 & 9 & 9 & 11 & 12 & 12 & 13 & 14 \\
\hline 13 & 15 & 15,5 & 15 & 15 & 13 & 10 & 10 & 12 & 13 & 13 & 14 & 15 \\
\hline 14 & 17 & 17,5 & 17 & 17 & 15 & 12 & 12 & 14 & 15 & 15 & 16 & 17 \\
\hline 15 & 16,5 & 17 & 16,5 & 16,5 & 14,5 & 11,5 & 11,5 & 13,5 & 14,5 & 14,5 & 15,5 & 16,5 \\
\hline 16 & 16 & 16,5 & 16 & 16 & 14 & 11 & 11 & 13 & 14 & 14 & 15 & 16 \\
\hline 17 & 15 & 15,5 & 15 & 15 & 13 & 10 & 10 & 12 & 13 & 13 & 14 & 15 \\
\hline 18 & 17 & 17,5 & 17 & 17 & 15 & 12 & 12 & 14 & 15 & 15 & 16 & 17 \\
\hline 19 & 18 & 18,5 & 18 & 18 & 16 & 13 & 13 & 15 & 16 & 16 & 17 & 18 \\
\hline 20 & 20 & 20 & 20 & 20 & 18 & 15 & 15 & 17 & 18 & 18 & 19 & 20 \\
\hline 21 & 19 & 19,5 & 19 & 19 & 17 & 14 & 14 & 16 & 17 & 17 & 18 & 19 \\
\hline 22 & 16 & 16,5 & 16 & 16 & 14 & 11 & 11 & 13 & 14 & 14 & 15 & 16 \\
\hline 23 & 15 & 15,5 & 15 & 15 & 13 & 10 & 10 & 12 & 13 & 13 & 14 & 15 \\
\hline 24 & 9 & 9,5 & 9 & 9 & 7 & 4 & 4 & 6 & 7 & 7 & 8 & 9 \\
\hline
\end{tabular}

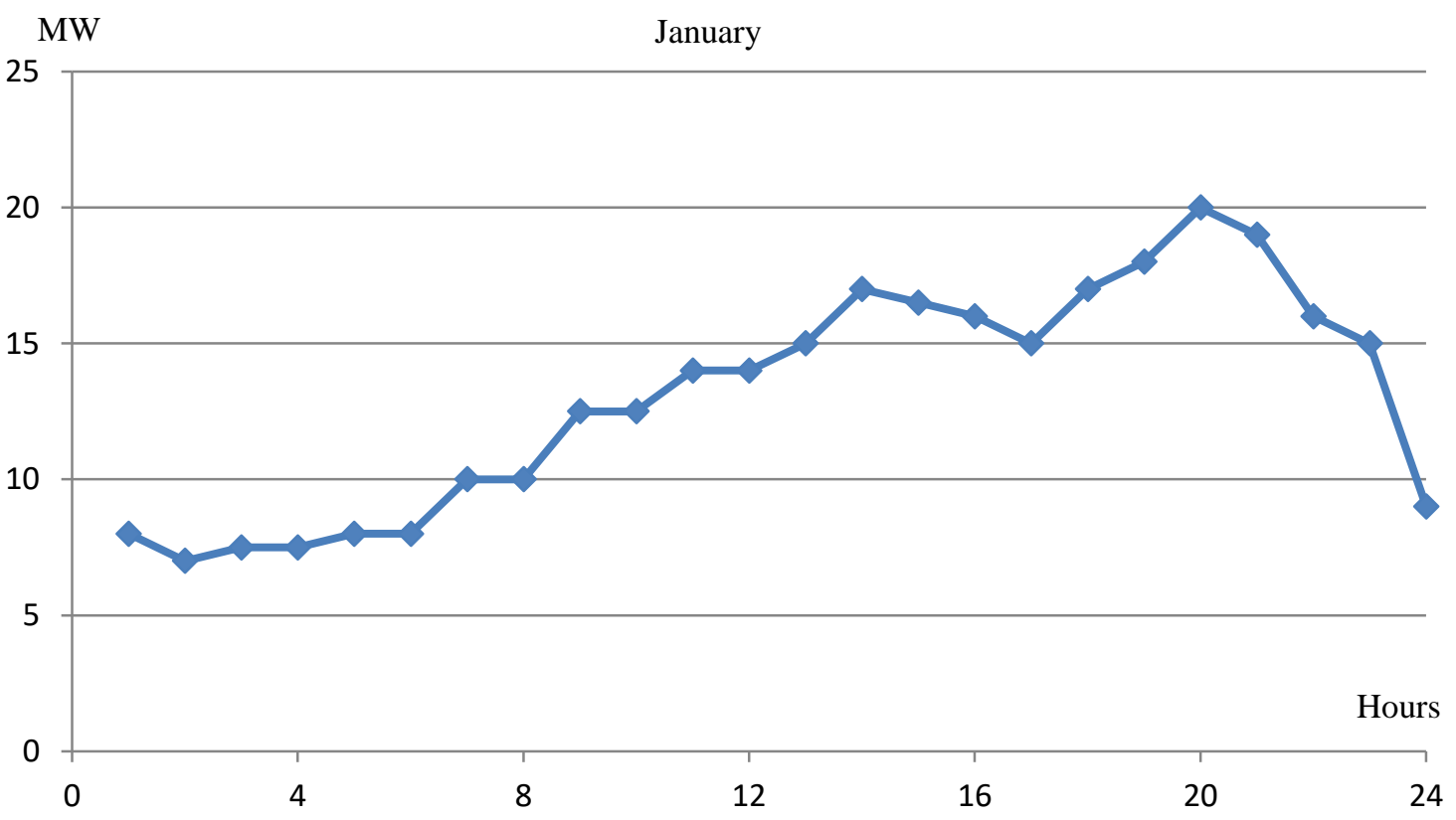

Fig. 5. Graphs of electrical load of an isolated consumer in January 


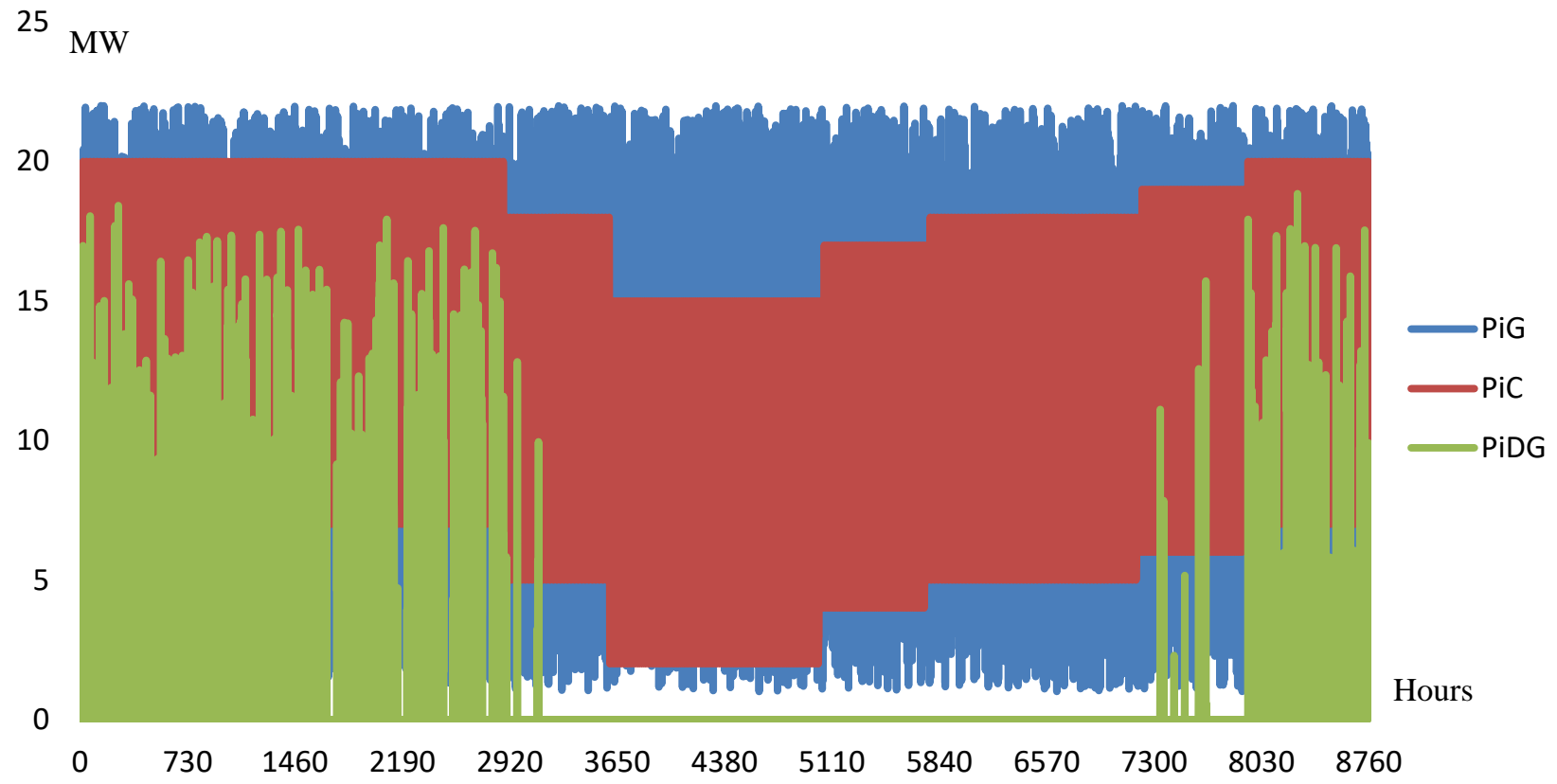

Fig. 6. Graphs of RES generation $\left(\mathrm{P}_{\mathrm{iG}}\right)$, diesel generation $\left(\mathrm{P}_{\mathrm{iDG}}\right)$ and electrical load $\left(\mathrm{P}_{\mathrm{iC}}\right)$

In Fig. 6, we can see that the DG is in operation mainly in the winter season, when the consumer load decreases. From the DG work schedule, you can already determine its approximate capacity.

In Fig. 7 shows the amount of energy in storage during the year. In the period from 3000 hours to 7300 hours, the limit of accumulated energy is reached, which, possibly, is a reason for increasing the volume of storage devices, but this requires an economic comparison of the option using storage capacity and without increasing it; it will not be carried out in this work.

The compiled model, and the computational experiment carried out on its basis, does not allow determining subsidies for consumers; additions to the model are needed:

1. The most priority task is to add a heat and hydrogen consumer to the model, without this determination of the optimal composition of equipment it makes no sense.

2. It is necessary to take into account some technical points that had to be neglected.

2.1 DG is usually connected to the network when the amount of energy in the storage becomes $20 \%$ less. At what amount of energy it will be included in the hydrogen system requires clarification and justification.

2.2 It is necessary to take into account the limitation on the amount of stored energy per hour. Separately for hydrogen storage, separately for $\mathrm{AB}$.

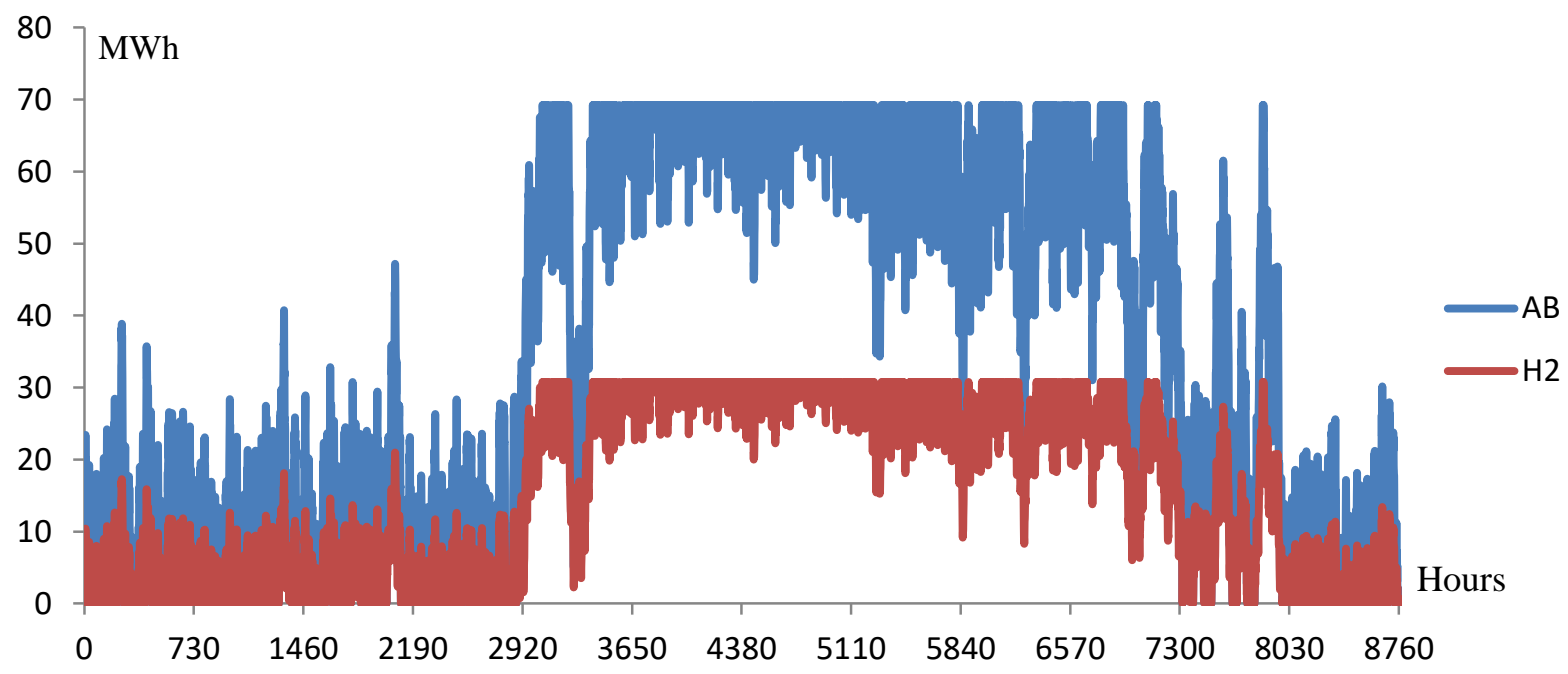

Fig. 7. Total stored energy in hydrogen $(\mathrm{H} 2)$ and $A B$ 


\section{Conclusion}

When analyzing the results of a computational experiment obtained on the basis of the developed model, it was concluded that it is impossible to solve the problem due to insufficiently complete consideration of the composition of the equipment of the considered power supply system of consumers, the characteristics of such equipment, ranges and conditions of its operation.

The system under consideration must be supplemented with equipment to meet the needs for thermal energy and motor fuel. In the system operation model, technical limitations should be taken into account in order to obtain more accurate estimates of the equipment composition - for example, such as limitations on the beginning and duration of battery charging, limitations on the minimum volume of gas in the hydrogen storage, taking into account the battery leakage currents and the loss of hydrogen in the hydrogen storage. In addition, it is necessary to clarify the methodology for determining the optimal composition of equipment for such an isolated power system.

The research was carried out under State Assignment Project (no. FWEU-2021-0004) of the Fundamental Research Program of Russian Federation 2021-2025

\section{References}

1 Timur Gül, Dave Turk, Maria Belen Simon Bennett, Uwe Remme, The Future of Hydrogen (IEA, June 2019).

2 T. Mitrova, Y. Melnikov, D. Chugunov, Hydrogen economy - albeit towards low-carbon development (June 2016)

3 R.V. Radchenko, A.S. Mokrushin, V.V. Tulip, Hydrogen in power engineering (2014)

4 Hydrogen fuel, available at: https://neftegaz.ru/techlibrary/energoresursy-toplivo/142374-vodorodnoetoplivo/ (accessed 10.06.2021)

5 Wind of a new generation, available at: https://plus.rbc.ru/news/5dfc32337a8aa9fb58ec3be8, (accessed 10.06.2021)

6 Green energy in Russia may become cheaper than traditional available at: https://www.vedomosti.ru/business/articles/2020/05/26/8 31097-zelenaya-energiya-v-rossii-vskore-mozhet-statdeshevle-traditsionnoi (accessed 10.06.2021) 